\title{
Digital TV signal reception and amplification system
}

\author{
A. Raizer \\ M. P. Fonseca
}




\title{
Digital TV signal reception and amplification system
}

\author{
A. Raizer and M. P. Fonseca
}

\begin{abstract}
This paper presents the development of an amplification system and two antennas for the reception of Digital TV signals. The proposed antennas are based on the halfwave dipole topology $(\lambda / 2)$ with geometry inspired by the meander line antenna (MLA) and magnetic loop antenna. Simulations using software based on the finite element method were performed. The antenna reception and efficiency of amplification system were evaluated through measurements.
\end{abstract}

Index Terms-Antenna Development, ISBT-Tb, HDTV, Meander Line Antenna (MLA), Radio-Frequency Amplifier Development

\section{INTRODUCTION}

$\mathrm{T}$ he Digital TV market has recently experienced substantial growth due to the transition from analogue to digital television transmission. In line with this change, the demanded reception of Digital TV signals increase researches for reception systems that can span large frequency ranges with low production costs.

The development and production of antennas with these characteristics impose the modification and use of high cost tools and mechanical processes, where directivity and gain of the antennas are opposed to the costs of production.

However, with the advancement of electronics and microelectronics, the costs of developing and manufacturing high-performance electronic devices for reception and amplification of Digital TV signals became lower than the amount invested to improve mechanical manufacturing processes for antennas, achieving better performances and versatility in their use.

This paper presents the development and testing of a radio frequency amplifier and two reference antennas, operating in the range of $470 \mathrm{MHz}$ to $806 \mathrm{MHz}$, intended for reception and amplification of the Digital TV signal in ISDB-Tb standard (Integrated Services Digital Broadcasting Terrestrial Brazilian), also known as SBTVD (Brazilian Digital Television System). To verify amplifier circuit performance, measurements were performed using specific test and

This paper was supported financially by the company W3Sat through the research project titled "Development of antennas for reception of digital signals on high definition television (HDTV)".

A. Raizer (adroaldo.raizer@ufsc.br) and M. P. Fonseca (gerencia.maglab@contato.ufsc.br), are within GEMCO - Engineering and Electromagnetic Compatibility Group; MagLab - Electromagnetism and Electromagnetic Compatibility Laboratory; Federal University of Santa Catarina (UFSC); P.O.Box 5024; Florianópolis-SC, Brazil, ZIP Code 88040970 . measurement equipment for radio frequency and digital TV reception systems.

\section{DEVELOPMENT OF THE RADIO FREQUENCY AMPLIFIER CIRCUIT}

The amplifier circuit has been developed to increase the levels of received Digital TV signals that are transmitted in the range of $470 \mathrm{MHz}$ to $806 \mathrm{MHz}$, based on ISDB-Tb standards. In addition to increase the signal level, the amplifier was designed in a way to not degrade the value of Bit Error Rate (BER) or Modulation Error Rate (MER).

The electronic circuit was developed using the ERA-3SM + monolithic amplifier as its basis. This component is a broadband amplifier that offers high dynamic range, with Micro-X encapsulation, using the transistors in Darlington configuration and manufactured using the $\mathrm{InGaP}$ HBT technology (indium-gallium-phosphide heterojunction bipolar transistor). This integrated circuit operates in the frequency range of $0 \mathrm{~Hz}(\mathrm{DC})$ to $3 \mathrm{GHz}$, with noise figure $<2,9 \mathrm{~dB}$, maximum gain variation with temperature rise of $-0.013 \mathrm{~dB} /{ }^{\circ}$ $\mathrm{C}$ and operation in temperature range from $-45^{\circ} \mathrm{C}$ to $85^{\circ} \mathrm{C}$.

With these specifications, the amplifier circuit was elaborated as shown in Fig.1.

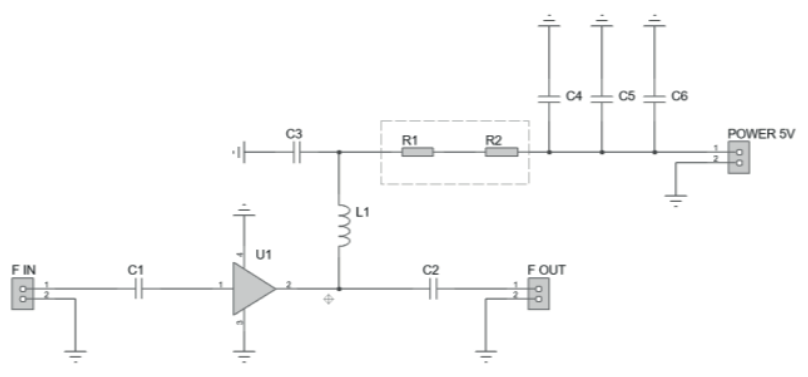

Fig. 1. Radio frequency amplifier electrical circuit.

\section{A. Circuit Supply}

Based on the availability of inputs and outputs of current televisions, the circuit power was designed to operate with nominal voltage of $5 \mathrm{~V}_{\mathrm{DC}}$. With this level of voltage for operation, it can power the device directly through a USB port included on television, without an external power supply. In this circuit configuration, it is also possible to power the amplifier circuit with voltages between $3.2 \mathrm{~V}_{\mathrm{DC}}$ to $12 \mathrm{~V}_{\mathrm{DC}}$, which allows operation in different scenarios. 


\section{B. Input and Output Impedance of Amplifier Circuit}

ERA-3SM+ integrated circuit operates with $50 \Omega$ input and output impedance, where an impedance matching was required to maximize power transfer of the signal, since the nominal impedance of TV system is $75 \Omega$. For this end, an Lnetwork matching impedance was elaborated at the input and output of the integrated circuit. The simplified circuit is shown in Fig. 2.

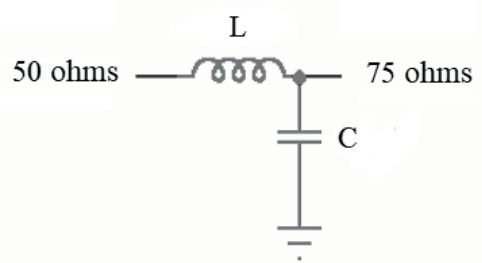

Fig. 2 - Simplified circuit of an L-network impedance matching.

This circuit was developed using the microstrip impedance matching technique [1], which uses the layout of the printed circuit board (PCB) to produce capacitive and inductive effects, which dispense use of physical components, as shown in Fig. 3.

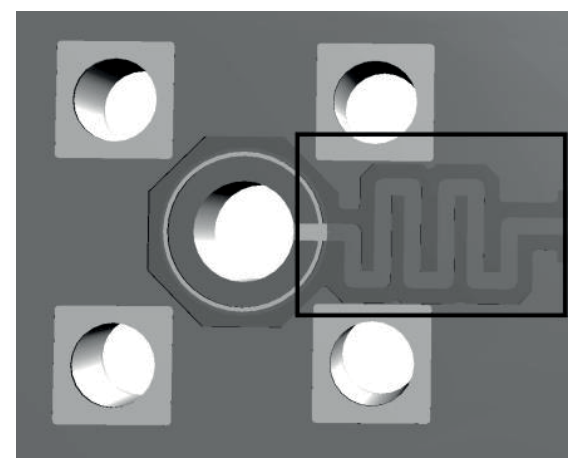

Fig. 3. L-network impedance matching using microstrip on PCI.

\section{DEVELOPMENT OF ANTENNAS FOR Digital TV}

Two antennas were developed to be used as references for the reception of Digital TV signals. These antennas were based on two common topologies: half-wave electric dipole with $(\lambda / 2)$ with meander line topology and magnetic dipole (loop).

\section{A. Half-Wave Electric Dipole (ג/2) with Meander Line Topology}

For the development of this antenna, the half-wave electric dipole $(\lambda / 2)$ was used. This configuration consists of two conductors with a central signal supply, where the distribution of the electromagnetic fields is generated by the potential difference between the two constituent antenna elements [2]. The radiation pattern of a theoretical half-wave dipole is shown in Fig. 4, where the upper and lower lobes can be observed, which demonstrates the maximum antenna directivity.

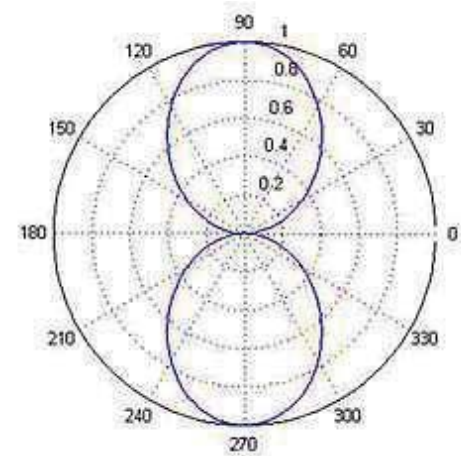

Fig. 4. Theoretical half-wave dipole $(\lambda / 2)$ radiation pattern.

Based on the exposed theory and antenna topology meander line [2], [3], the antenna for reception of Digital TV signals in the frequencies of $470 \mathrm{MHz}$ to $806 \mathrm{MHz}$ was developed. This type of topology has been widely used, since it helps reduce antenna length [2], [3]. This dimensional reduction is obtained due to the fact that the structure is constituted by a set of rectangular arrays, which possibilities the reduction of the resonance frequency and the increase of the radiation resistance in relation to a conventional dipole.

To calculate dimensions of this structure, the theory presented in [2] was used. The obtained antenna structure is shown in Fig. 5.
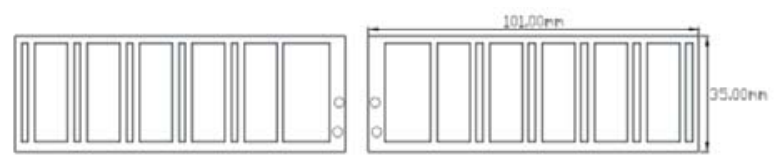

Fig. 5. Developed meander line antenna.

\section{B. Magnetic Dipole Antenna (loop)}

The magnetic dipole antenna (loop) was developed based on the theory exposed in [4]. It is constituted by a radiant element that is divided, usually in the center, to allow a feeder to apply energy from a transmitter, or to be transferred to a receiver. The length of the radiant element determines many of the dipole antenna properties, such as impedance and central frequency of operation. This is an important characteristic of the antenna, which allows various configurations and antenna formats.

Based on the exposed theory, the antenna for the reception of Digital TV signals, shown in Fig. 6, was developed in the frequencies of Digital TV.

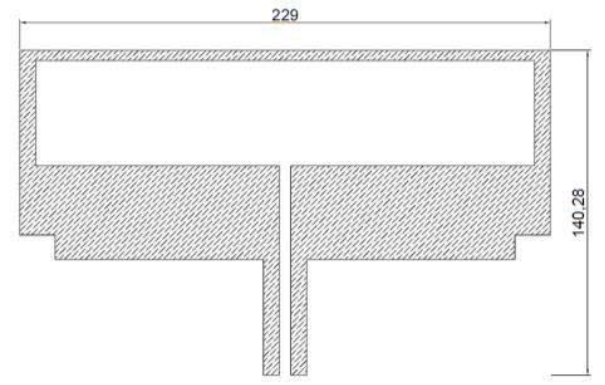

Fig. 6. Developed magnetic dipole antenna. 


\section{Modeling by Finite Elements}

For perform the modeling of the antennas developed, software based on the finite element method [5] was utilized. As can be seen in Fig. 7 and Fig. 8, the antennas were modeled and simulated with the physical and geometrical characteristics according to the development described previously.

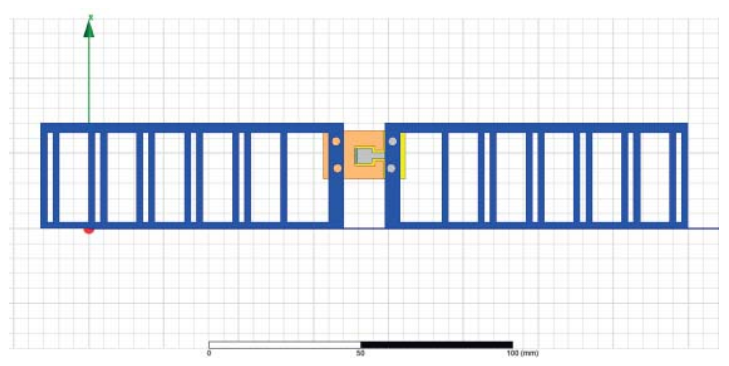

Fig. 7. Simulated meander line antenna.

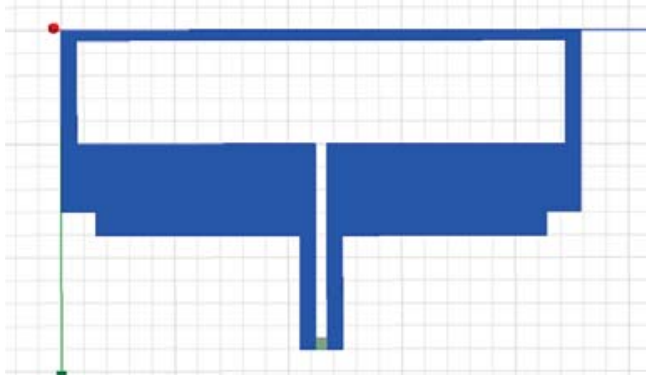

Fig. 8. Simulated magnetic dipole antenna.

\section{Simulation of Radiation Pattern}

With antennas modeling, simulations of radiation pattern were performed for $470 \mathrm{MHz}$ and $806 \mathrm{MHz}$ frequencies, as can be seen in Fig. 9 and Fig. 10 for the electric dipole antenna with meander line topology, and Fig. 11 and Fig. 12 for the Magnetic dipole antenna with loop topology. From the analysis of the presented radiation pattern, it is possible to verify through the lobes of $\phi=0^{\circ}$ (red) and $\phi=90^{\circ}$ (blue), that in the plane $\mathrm{y}=0$, both developed antennas have maximum directivity, and angulation with respect to the y axis indicates the presence of higher modes.

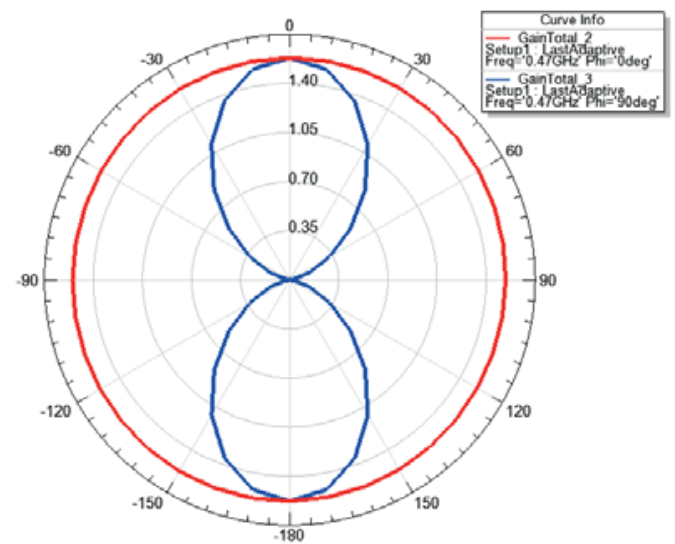

Fig. 9. Meander line antenna radiation pattern for frequency $470 \mathrm{MHz}, \phi=0^{\circ}$ and $\phi=90^{\circ}$.

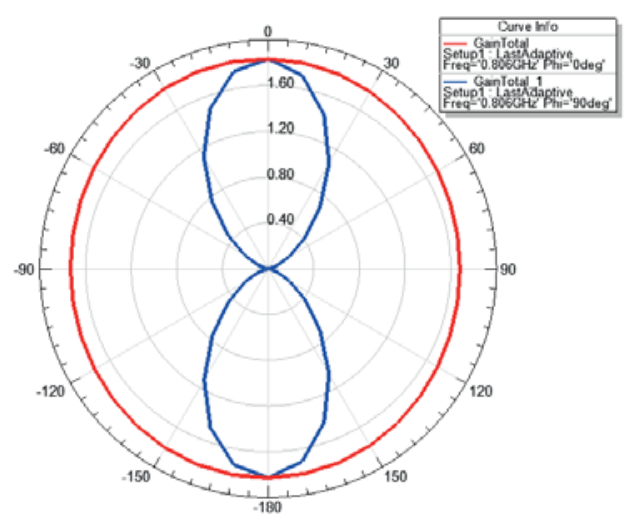

Fig. 10. Meander line antenna radiation pattern for frequency $806 \mathrm{MHz}, \phi=0^{\circ}$ and $\phi=90^{\circ}$.

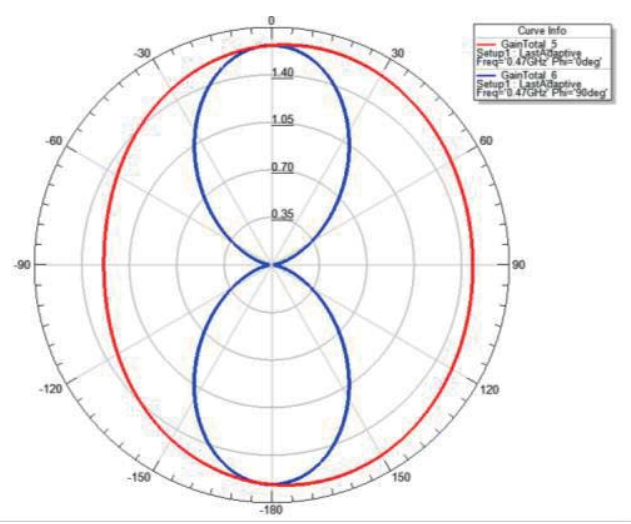

Fig. 11. Loop antenna radiation pattern for frequency $470 \mathrm{MHz}, \phi=0^{\circ}$ and $\phi=90^{\circ}$.

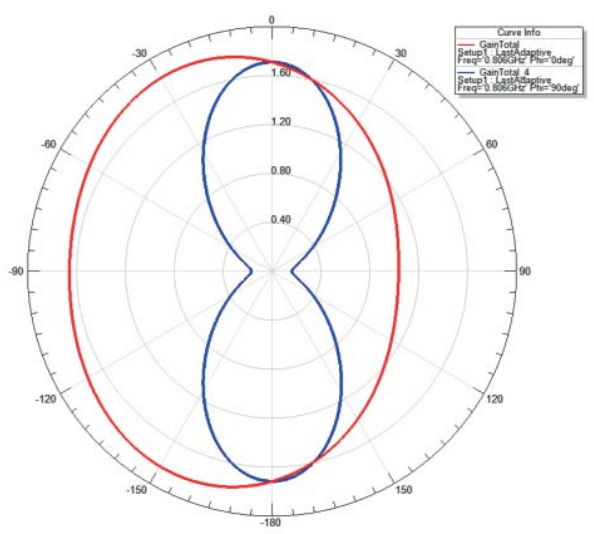

Fig. 12. Loop antenna radiation pattern for frequency $806 \mathrm{MHz}, \phi=0^{\circ}$ and $\phi=90^{\circ}$.

Compared with the theoretical pattern presented in Fig. 4, it can be observed that the developed antennas have their performance according to the characteristics of respective types of topology. After the simulations and parameters extraction, both antennas were made in aluminum. 


\section{MEASUREMENTS}

For amplifier circuit evaluation, measurements were performed of return loss, gain in continuous wave $(\mathrm{CW})$, gain in Digital TV channel, MER and BER. Measurements of gains in Digital TV channel, MER and BER were performed in two steps. Initially were performed only with antennas, in order to verify the values of each parameter without the use of the amplifier circuit. Afterwards, same measurements were performed using the amplifier circuit and the variations of the measured parameters were analyzed.

\section{A. Measurements of Return Loss}

Using a vector network analyzer, model ZNB4 (Rohde \& Schwarz), return loss was measured as shown in Fig. 13. This measurement presents the $S_{11}$ parameter, which characterize the reflection coefficient of the amplifier circuit input, and can be presented in logarithmic scale as return loss.

As shown in Fig. 13, the result presents a return loss $\leq-$ $15 \mathrm{~dB}$, which guarantee $\geq 97 \%$ power transfer.

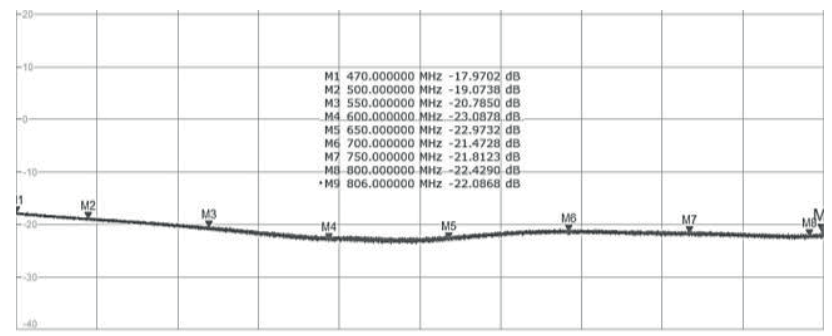

Fig. 13 - Circuit amplifier return loss $\left(\mathrm{S}_{11}\right)$.

\section{B. Gain in Continuous Wave (CW)}

Using the same equipment, the amplifier circuit gain in continuous wave (CW), was measured, as shown in Fig. 14. This measurement characterizes the $S_{21}$ parameter of the amplifier circuit, which indicates the voltage gain value of output signal in relation to the input signal for the Digital TV frequency range.

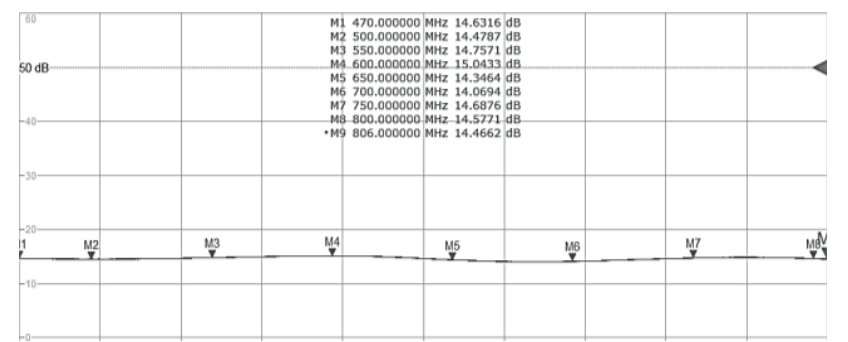

Fig. 14 - Gain in $\mathrm{CW}\left(\mathrm{S}_{21}\right)$

As can be observed in Fig. 14, the amplifier circuit gain in continuous wave $(\mathrm{CW})$ has a mean value of $14.58 \mathrm{~dB}$ in Digital TV frequency range.

\section{Measurements of Gain in Open Digital TV Channel}

Gain in open Digital TV channels available between the frequencies of $470 \mathrm{MHz}$ to $806 \mathrm{MHz}$, shown in table 1, were measured.

For this measurement, a Digital TV Analyzer, model ETH (Rohde \& Schwarz), was used for measure the power of open channels of Digital TV. Measurements were performed using only the receiving antennas and subsequent measurement of channel power using the amplifier circuit. The results obtained are described in table 2 with meander line antenna use and in table 3 with loop antenna use.

Table 1 - Open Digital TV Channels
\begin{tabular}{|c|c|c|c|}
\hline Transmitter & $\begin{array}{c}\text { Frequency } \\
(\mathrm{MHz})\end{array}$ & $\begin{array}{c}\text { Virtual } \\
\text { Channel }\end{array}$ & $\begin{array}{c}\text { Physical } \\
\text { Channel }\end{array}$ \\
\hline 1 & 515.143 & 20.1 & 21 \\
\hline 2 & 521.143 & 23.1 & 22 \\
\hline 3 & 569.143 & 4.1 & 30 \\
\hline 4 & 575.143 & 6.1 & 31 \\
\hline 5 & 581.143 & 9.1 & 32 \\
\hline 6 & 587.143 & 12.1 & 33 \\
\hline 7 & 641.143 & 43.1 & 42 \\
\hline 8 & 665.143 & 45.1 & 46 \\
\hline 9 & 755.143 & 61.1 & 61 \\
\hline 10 & 767.143 & 63.1 & 63 \\
\hline
\end{tabular}

Table 2 - Measurement of power in the open channels of Digital TV with meander line antenna.

\begin{tabular}{|c|c|c|c|}
\hline Transmitter & $\begin{array}{c}\text { Power without } \\
\text { amplifier } \\
(\mathrm{dBm})\end{array}$ & $\begin{array}{c}\text { Power with } \\
\text { amplifier } \\
(\mathrm{dBm})\end{array}$ & $\begin{array}{c}\text { Gain } \\
(\mathrm{dB})\end{array}$ \\
\hline 1 & -67.34 & -55.99 & 11.35 \\
\hline 2 & -76.34 & -61.29 & 15.05 \\
\hline 3 & -60.80 & -46.77 & 14.03 \\
\hline 4 & -73.37 & -60.32 & 13.05 \\
\hline 5 & -58.57 & -45.62 & 12.95 \\
\hline 6 & -60.40 & -45.85 & 14.55 \\
\hline 7 & -72.56 & -60.54 & 12.02 \\
\hline 8 & -66.80 & -54.73 & 12.07 \\
\hline 9 & -62.08 & -46.36 & 15.72 \\
\hline 10 & -75.95 & -62.01 & 13.94 \\
\hline
\end{tabular}

Table 3 - Measurement of power gain in the open channels of Digital TV with loop antenna

\begin{tabular}{|c|c|c|c|}
\hline Transmitter & $\begin{array}{c}\text { Power without } \\
\text { amplifier } \\
(\mathrm{dBm})\end{array}$ & $\begin{array}{c}\text { Power with } \\
\text { amplifier } \\
(\mathrm{dBm})\end{array}$ & $\begin{array}{c}\text { Gain } \\
(\mathrm{dB})\end{array}$ \\
\hline 1 & -69.80 & -57.06 & 12.74 \\
\hline 2 & -76.45 & -62.46 & 13.99 \\
\hline 3 & -58.76 & -44.07 & 14.69 \\
\hline 4 & -74.81 & -61.81 & 13.00 \\
\hline 5 & -66.01 & -48.65 & 17.36 \\
\hline 6 & -62.79 & -46.39 & 16.40 \\
\hline 7 & -73.86 & -60.06 & 13.80 \\
\hline 8 & -65.30 & -48.73 & 16.57 \\
\hline 9 & -68.66 & -53.89 & 14.77 \\
\hline 10 & -78.52 & -63.46 & 15.06 \\
\hline
\end{tabular}

The power gain in the open channels of Digital TV with meander line antenna has a mean value of $13.47 \mathrm{~dB}$, and power gain in the open channels of Digital TV with loop antenna has a mean value of $14.84 \mathrm{~dB}$, as presented in table 2 and table 3 . 


\section{MER Measurements}

The Modulation Error Rate (MER) is defined as the ratio between the square of the ideal pairs of the digital modulation symbols measured and the square of the error pairs [4]. Therefore, the MER is related to the SNR (Signal Noise Ratio) and allows the evaluation of the quality of the received signal.

Using the ETH, the values of MER were measured for the transmission layers A and B. Initially the measurement was performed only with the receiving antennas and subsequently measured using the amplifier circuit. The values measured with the meander line antenna are shown in Tables 4 and 5, and the values measured with the loop antenna are shown in Tables 6 and 7.

Table 4 - Measurement of MER with and without the amplifier in open channels of Digital TV for layer A with meander line antenna

\begin{tabular}{|c|c|c|}
\hline $\begin{array}{c}\text { Transmitter } \\
\text { (layer A) }\end{array}$ & $\begin{array}{c}\text { MER without } \\
\text { amplifier } \\
(\mathrm{dB})\end{array}$ & $\begin{array}{c}\text { MER with } \\
\text { amplifier } \\
(\mathrm{dB})\end{array}$ \\
\hline 1 & 19.4 & 19.5 \\
\hline 2 & 11.6 & 15.9 \\
\hline 3 & 24.2 & 28.8 \\
\hline 4 & 13.7 & 14.7 \\
\hline 5 & 20.0 & 20.0 \\
\hline 6 & 22.4 & 30.9 \\
\hline 7 & 7.1 & 15.9 \\
\hline 8 & 20.9 & 21.1 \\
\hline 9 & 23.5 & 33.5 \\
\hline 10 & 15.9 & 23,9 \\
\hline
\end{tabular}

Table 5 - Measurement of MER with and without the amplifier in open channels of Digital TV for layer B with meander line antenna

\begin{tabular}{|c|c|c|}
\hline $\begin{array}{c}\text { Transmitter } \\
\text { (layer B) }\end{array}$ & $\begin{array}{c}\text { MER without } \\
\text { amplifier } \\
(\mathrm{dB})\end{array}$ & $\begin{array}{c}\text { MER with } \\
\text { amplifier } \\
(\mathrm{dB})\end{array}$ \\
\hline 1 & 17.6 & 20.1 \\
\hline 2 & 11.9 & 15.3 \\
\hline 3 & 19.6 & 26.7 \\
\hline 4 & 12.1 & 15.4 \\
\hline 5 & 20.2 & 20.5 \\
\hline 6 & 26.8 & 27.6 \\
\hline 7 & 16.1 & 19.0 \\
\hline 8 & 17.1 & 22.3 \\
\hline 9 & 22.7 & 28.2 \\
\hline 10 & 11.3 & 17.4 \\
\hline
\end{tabular}

Table 6 - Measurement of MER with and without the amplifier in open channels of Digital TV for layer A with loop antenna

\begin{tabular}{|c|c|c|}
\hline $\begin{array}{c}\text { Transmitter } \\
\text { (layer A) }\end{array}$ & $\begin{array}{c}\text { MER without } \\
\text { amplifier } \\
(\mathrm{dB})\end{array}$ & $\begin{array}{c}\text { MER with } \\
\text { amplifier } \\
(\mathrm{dB})\end{array}$ \\
\hline 1 & 11.6 & 15.4 \\
\hline 2 & 11.5 & 13.3 \\
\hline 3 & 16.3 & 27.2 \\
\hline 4 & 12.2 & 12.3 \\
\hline 5 & 10.6 & 29.8 \\
\hline 6 & 18.3 & 30.9 \\
\hline 7 & 16.5 & 19.2 \\
\hline 8 & 19.4 & 32.7 \\
\hline 9 & 16.2 & 22.0 \\
\hline 10 & 11.7 & 18.0 \\
\hline
\end{tabular}

Table 7 - Measurement of MER with and without the amplifier in open channels of Digital TV for layer B with loop antenna

\begin{tabular}{|c|c|c|}
\hline $\begin{array}{c}\text { Transmitter } \\
\text { (layer B) }\end{array}$ & $\begin{array}{c}\text { MER without } \\
\text { amplifier } \\
(\mathrm{dB})\end{array}$ & $\begin{array}{c}\text { MER with } \\
\text { amplifier } \\
(\mathrm{dB})\end{array}$ \\
\hline 1 & 13.9 & 19.0 \\
\hline 2 & 11.7 & 14.6 \\
\hline 3 & 25.2 & 27.8 \\
\hline 4 & 12.6 & 17.0 \\
\hline 5 & 18.3 & 24.6 \\
\hline 6 & 22.3 & 28.8 \\
\hline 7 & 16.0 & 18.8 \\
\hline 8 & 20.6 & 30.3 \\
\hline 9 & 15.6 & 20.6 \\
\hline 10 & 10.5 & 14.6 \\
\hline
\end{tabular}

\section{E. BER Measurements}

The Bit Error Rate (BER) is one of the measures to characterize the statistical performance of a digital communication system. It is defined as the ratio between the number of error bits detected and the total number of bits received [7].

ETH emulates two error correction codes that receivers use, Viterbi and Reed Solomon [8] [9], which allows to perform BER measurements on each open digital TV channel, with and without the amplifier circuit. The measurements are presented in tables 8 and 9 using the meander line antenna, and table 10 and 11 using the loop antenna.

Table 7 - BER measurement with and without the amplifier in open channels of Digital TV for layer A with meander line antenna

\begin{tabular}{|c|c|c|}
\hline $\begin{array}{c}\text { Transmitter } \\
(\text { layer A) }\end{array}$ & $\begin{array}{c}\text { BER without } \\
\text { amplifier } \\
(\mathrm{ppm})\end{array}$ & $\begin{array}{c}\text { BER with } \\
\text { amplifier } \\
(\mathrm{ppm})\end{array}$ \\
\hline 1 & 0.0 & 0.0 \\
\hline 2 & 0.0 & 0.0 \\
\hline 3 & 0.0 & 0.0 \\
\hline 4 & 0.0 & 0.0 \\
\hline 5 & 0.0 & 0.0 \\
\hline 6 & 0.0 & 0.0 \\
\hline 7 & 0.0 & 0.0 \\
\hline 8 & 0.0 & 0.0 \\
\hline 9 & 0.0 & 0.0 \\
\hline 10 & 0.0 & 0.0 \\
\hline
\end{tabular}

Table 8 - BER measurement with and without the amplifier in open channels of Digital TV for layer B with meander line antenna

\begin{tabular}{|c|c|c|}
\hline $\begin{array}{c}\text { Transmitter } \\
\text { (layer B) }\end{array}$ & $\begin{array}{c}\text { BER without } \\
\text { amplifier } \\
(\mathrm{ppm})\end{array}$ & $\begin{array}{c}\text { BER with } \\
\text { amplifier } \\
(\mathrm{ppm})\end{array}$ \\
\hline 1 & 0.0 & 0.0 \\
\hline 2 & 0.0 & 0.0 \\
\hline 3 & 0.0 & 0.0 \\
\hline 4 & 5,900 & 900 \\
\hline 5 & 0.2 & 0.0 \\
\hline 6 & 0.0 & 0.0 \\
\hline 7 & 5,900 & 840 \\
\hline 8 & 0.0 & 0.0 \\
\hline 9 & 0.0 & 0.0 \\
\hline 10 & 2,200 & 0.0 \\
\hline
\end{tabular}


Table 9 - BER measurement with and without the amplifier in open channels of Digital TV for layer a with loop antenna

\begin{tabular}{|c|c|c|}
\hline $\begin{array}{c}\text { Transmitter } \\
\text { (layer B) }\end{array}$ & $\begin{array}{c}\text { BER without } \\
\text { amplifier } \\
(\mathrm{ppm})\end{array}$ & $\begin{array}{c}\text { BER with } \\
\text { amplifier } \\
\text { (ppm) }\end{array}$ \\
\hline 1 & 0.0 & 0.0 \\
\hline 2 & 0.0 & 0.0 \\
\hline 3 & 0.0 & 0.0 \\
\hline 4 & 0.0 & 0.0 \\
\hline 5 & 0.0 & 0.0 \\
\hline 6 & 0.0 & 0.0 \\
\hline 7 & 0.0 & 0.0 \\
\hline 8 & 0.0 & 0.0 \\
\hline 9 & 0.0 & 0.0 \\
\hline 10 & 0.0 & 0.0 \\
\hline
\end{tabular}

Table 10 - BER measurement with and without the amplifier in open channels of Digital TV for layer B with loop antenna

\begin{tabular}{|c|c|c|}
\hline $\begin{array}{c}\text { Transmitter } \\
\text { (layer B) }\end{array}$ & $\begin{array}{c}\text { BER without } \\
\text { amplifier } \\
(\mathrm{ppm})\end{array}$ & $\begin{array}{c}\text { BER with } \\
\text { amplifier } \\
(\mathrm{ppm})\end{array}$ \\
\hline 1 & 0.0 & 0.0 \\
\hline 2 & 0.0 & 0.0 \\
\hline 3 & 0.0 & 0.0 \\
\hline 4 & 3,700 & 50 \\
\hline 5 & 3.7 & 53 \\
\hline 6 & 0.0 & 0.0 \\
\hline 7 & 5,900 & 1.300 \\
\hline 8 & 0.0 & 0.0 \\
\hline 9 & 3.8 & 0.0 \\
\hline 10 & 5,900 & 0.0 \\
\hline
\end{tabular}

\section{CONCLUSION}

In this paper are shown the development and measurements of an amplifier circuit, a half-wave dipole antenna $(\lambda / 2)$ with a geometric structure based on the meander line antenna and a magnetic loop dipole antenna, all with the purpose of receiving digital TV signals.

The development and measurements of amplifier circuit allowed the amplification of the signals and presented linearity in gain in the frequency range of operation. With the gain values, the amplifier circuit demonstrated versatility in its use, since it can be used in environments where there is low signal quality, such as non-metropolitan environments.

Through the simulations and measurements performed in the antennas, it can be verified that the structures present satisfactory results in relation to the reception of Digital TV signals.

The use of the amplifier circuit has contributed to increase the levels of MER for the open channels of Digital TV, improving the quality of the signals received. BER levels were also improved, which reduce the amount of wrong bits received using the same circuit.

In this way, the use of amplified Digital TV signal reception systems is encouraged, in order to improve the amplitude and quality of the signals received and the low cost for the development of electronic systems.

Therefore, it is important to note that studies related to the Digital TV reception system of small size and high performance should become more important in the present times, especially considering the imminent end of analog signals.

\section{REFERENCES}

[1] R. Fralich, J. Wang, J. Litva, "An optimized impedance-matching technique for increasing the bandwidth of microstrip antenna", in Symposium on Antenna Technology and Applied Electromagnetics, 1990. Antem 1990.

[2] K. W CHEN, C. L. YANG, A Method for Input Impendence Matching of PIFA based on Meander Line Antenna, International Symposium on Antennas and Propagation (ISAP), 2- 5 December , 2014.

[3] D. MISMAN, M.N. HUSAIN; M.Z.A ABD AZIZ,.., I.A. KADIR, M.F.A. SALAMAT, M.R.C. ROSE; M. SHAH; P.J. SOH, The Study of a Different Impedance Meander Line for Microstrip Antenna Design, 6th National Conference on Telecommunication Technologies 2008 and 2008 2nd Malaysia Conference on Photonics. NCTT-MCP, 26-28 August, 2008.

[4]Balanis, C.A., "Wire Elements: Dipoles, Monopoles and Loops" in Modern Antenna Handbook, USA, 2008

[5] (2014). ANSYS HFSS website. [Online]. Available: http://www.ansys.com/Products/Simulation+Technology/Electronics/Signal+I ntegrity/ANSYS+HFSS

[6] Hui Tang, Xianrong Wan, Lina Hong, Wei Chen, Jianxin Yi, "Detection improvement by modified modulation error rate of Reference signal in passive radar", in URSI GASS, Beijing, China, 2014.

[7] A. J. Almeida , N. A. Silva, N. J. Muga, P. S. André, A. N. Pinto, "Calculation of the number of bits required for the estimation of the bit error ratio", in Proc. SPIE 9286, Portugal, 2014.

[8] Longlong $\mathrm{Wu}$, Yongjie Xie, Daping $\mathrm{Xu}, \mathrm{Li}$ Ren, "Ballistic Missile Precession Frequency Extraction Based on the Viterbi \& Kalman Algorithm”, in Proc. SPIE 9812, Enshi, China, 2015.

[9] Oksana Volivach, Anatoly Beletsky, "Reed-Solomon's algorithm and software for correcting errors in a text", in Proc. SPIE 8008, Wilga, Poland, 2008.

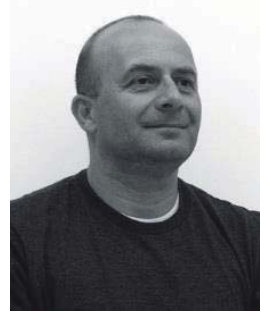

Adroaldo Raizer, was born in Lages, Santa Catarina, Brazil, on August 11, 1963. He received the titles of Electrical Engineer (1985) and master's degree in electrical engineering (1987), both from the Federal University of Santa Catarina. Completed his doctorate (1991) in Electrical Engineering by the Institut National Polytechnique de Grenoble, France. Currently Dr. Raizer is a full professor of the Department of Electrical and Electronic Engineering of the Federal University of Santa Catarina. He also works as coordinator of the Electromagnetic Compatibility and Engineering Group (GEMCO) and the Electromagnetic Compatibility and Electromagnetic Compatibility Laboratory (MagLab). His areas of interest are electromagnetic fields, electromagnetic compatibility and numerical methods.

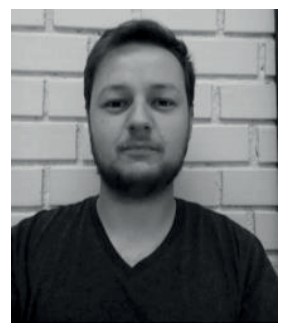

Mikael Pontes Fonseca, was born in Pelotas, Rio Grande do Sul, Brazil, on December 13, 1991. He received the title of Electronic Technician (2013) by the Federal Institute of Santa Catarina. He is currently Technical Manager of the Electromagnetism and Electromagnetic Compatibility Laboratory (MagLab). His areas of interest are electromagnetic fields, electromagnetic compatibility, automation and embedded systems.

Received in 2017-06-30 | Approved in 2017-11-07 